\title{
Rapid and Consistent Improvements in Morning PEF in Patients with Severe Eosinophilic Asthma Treated with Mepolizumab
}

\author{
Hector Ortega - Andrew Menzies-Gow - Jean-Pierre Llanos • \\ Mark Forshag · Frank Albers · Necdet Gunsoy • Eric S. Bradford • \\ Steven W. Yancey · Monica Kraft
}

Received: April 20, 2018 / Published online: June 15, 2018

(C) The Author(s) 2018

\section{ABSTRACT}

Introduction: Previous studies showed that mepolizumab significantly reduces exacerbations and oral corticosteroid use in patients with severe eosinophilic asthma. However, early studies reported inconsistent effects on lung function. This study specifically assessed the onset of clinical effect and the relationship of baseline blood eosinophil count of mepolizumab $100 \mathrm{mg}$ subcutaneous (SC) administration on morning peak expiratory flow (AM PEF).

Methods: Post hoc analysis of data from two randomized, double-blind, placebo-controlled studies (MENSA, NCT01691521; MUSCA,

Enhanced digital features To view enhanced digital features for this article go to https://doi.org/10.6084/m9 figshare.6384596.

Electronic supplementary material The online version of this article (https://doi.org/10.1007/s12325018-0727-8) contains supplementary material, which is available to authorized users.

H. Ortega $(\bowtie)$

Respiratory US Medical Affairs, GlaxoSmithKline, La Jolla, CA, USA

e-mail: hectorortega15@hotmail.com

\section{A. Menzies-Gow}

Respiratory Medicine, Royal Brompton Hospital, London, UK

J.-P. Llanos · M. Forshag

Respiratory US Medical Affairs, GlaxoSmithKline, Research Triangle Park, NC, USA
NCT02281318) of 4-weekly mepolizumab $100 \mathrm{mg}$ versus placebo in patients with severe eosinophilic asthma. Individual study results were generated using a mixed model repeated measures model controlling for multiple covariates and were combined using a fixed effects meta-analysis via inverse-variance weighting.

Results: Significant improvements in AM PEF after the first dose of mepolizumab $100 \mathrm{mg}$ SC vs. placebo were seen as early as week 1 and continued to improve further with subsequent doses. The mean change in AM PEF was $26 \mathrm{~L} /$ min in the mepolizumab group compared to $4 \mathrm{~L} / \mathrm{min}$ in the placebo group, $p<0.001$. When the population was stratified by blood eosinophil thresholds the mean difference from placebo was $24 \mathrm{~L} / \mathrm{min}$ ( $\geq 150$ cells $/ \mu \mathrm{L}), 27 \mathrm{~L} / \mathrm{min}$ ( $\geq 300$ cells $/ \mu \mathrm{L})$, and $34 \mathrm{~L} / \mathrm{min}(\geq 500$ cells $/ \mu \mathrm{L})$, $p<0.001$ for all subgroups. The $<150$ cells $/ \mu \mathrm{L}$ $(\geq 300$ cells $/ \mu \mathrm{L}$ in the previous year) group increased $13 \mathrm{~L} / \mathrm{min}$, while both 150 to $<300$

\author{
F. Albers · E. S. Bradford · S. W. Yancey \\ Respiratory Therapeutic Area Unit, \\ GlaxoSmithKline, Research Triangle Park, NC, USA \\ N. Gunsoy \\ Clinical Statistics, GlaxoSmithKline, Stockley Park, \\ Middlesex, UK \\ M. Kraft \\ Department of Medicine, University of Arizona, \\ Tucson, AZ, USA
}


cells $/ \mu \mathrm{L}$ and 300 to $<500$ cells $\mu \mathrm{L}$ ranges demonstrated comparable changes $(19 \mathrm{~L} / \mathrm{min}$ and $17 \mathrm{~L} / \mathrm{min}$ ), respectively.

Conclusion: Our analysis has shown early and consistent improvements in lung function measured by AM PEF using the study enrollment criterion of $\geq 150$ eosinophils $/ \mu \mathrm{L}$. We also identified a relationship between baseline blood eosinophils and improvements in AM PEF with mepolizumab in patients with severe eosinophilic asthma.

Funding: GlaxoSmithKline (study ID 208091).

Keywords: AM PEF; Anti-IL-5; Blood eosinophils; Lung function; Monoclonal antibody; Respiratory; Severe asthma

\section{INTRODUCTION}

Mepolizumab has been shown to reduce exacerbations [1-4] and oral corticosteroid use [5, 6], as well as to improve quality of life $[1,3,4,6]$ and asthma control [3, 4, 6]. However, lung function results were inconsistent in early studies $[1,2,7]$. For example, nearly a decade ago, Flood-Page and colleagues reported that mepolizumab treatment failed to show meaningful changes in the primary endpoint of morning peak expiratory flow (AM PEF). However, these patients were not selected using criteria now known to be associated with a positive treatment response to mepolizumab [7].

Our understanding of the severe eosinophilic asthma phenotype likely to respond to mepolizumab treatment was informed by a series of studies following the report by Flood-Page and colleagues which systematically refined the target population for mepolizumab treatment. In the proof of concept study by Haldar and colleagues [1] as well as the DREAM study [2] a significant reduction in exacerbations (approximately 50\%) was demonstrated, whereas changes in lung function were modest. The lack of effect on lung function may have resulted from the non-specific approach in selecting study participants. For example, DREAM allowed four different biomarkers to identify the eosinophilic phenotype. However, of these, only the baseline blood eosinophil count combined with the frequency of prior exacerbations was predictive in a modelling analysis of positive treatment response to mepolizumab, measured by the magnitude of the relative reduction in exacerbations compared with placebo [2]. These findings formed the basis of the clinical characteristics and the blood eosinophil thresholds now used to select patients for treatment with mepolizumab. As such, the more recent studies, MENSA (NCT01691521) and MUSCA (NCT02281318), utilized these key predictor characteristics to select study participants: blood eosinophil count of at least 150 cells $/ \mu \mathrm{L}$ at screening or 300 cells $/ \mu \mathrm{L}$ in the past 12 months, plus at least two exacerbations in the past 12 months despite high dose inhaled corticosteroid (ICS) and another controller medication $[3,4]$. These two studies also showed a reduction in exacerbations ranging from $52 \%$ to $58 \%$, and demonstrated improvements in quality of life, asthma control, and $\mathrm{FEV}_{1}[3,4]$.

Mepolizumab is an anti-interleukin (IL)-5 monoclonal antibody that is approved as an add-on therapy to standard of care for severe asthma in adolescents and adult patients with an eosinophilic phenotype $[8,9]$. This report describes the result of the individual studies as well as a meta-analysis of AM PEF from studies using both the commercialized dose of mepolizumab $100 \mathrm{mg}$ administered subcutaneously and the refined criteria which select patients likely to respond to mepolizumab treatment. In this post hoc analysis we also assess the onset of clinical effect and the relationship between baseline blood eosinophil count thresholds and lung function changes measured by AM PEF following treatment with mepolizumab.

\section{METHODS}

\section{Included Studies}

Criteria used for the inclusion of studies in the meta-analysis were placebo-controlled studies of mepolizumab $100 \mathrm{mg}$ SC in severe eosinophilic asthma in patients with two or more exacerbations in the past year; studies utilizing 
a blood eosinophil threshold of at least 150 cells $/ \mu \mathrm{L}$ at screening (or at least 300 cells $/ \mu \mathrm{L}$ in the previous year) to select the target population; dose of baseline asthma medications kept constant throughout study; and duration of at least 24 weeks. Studies included on the basis of these criteria were the MENSA study (GSK/ ClinicalTrials.gov identifier MEA115588/ NCT01691521) and the MUSCA study (Study 200862/NCT02281318) [3, 4]. The protocol for the current analysis is available from the GSK Clinical Study Register (number 208091) [10].

\section{Patients}

Enrollment criteria for the studies have been previously published [3, 4]. Briefly, patients were aged at least 12 years; required to have had a clinical diagnosis of asthma; had a history of at least two exacerbations requiring systemic corticosteroid treatment in the previous year, and disease severity consistent with the ERS/ATS definition for severe asthma [11, 12]. Eosinophilic inflammation was defined as a blood eosinophil count of at least 150 cells/ $\mu \mathrm{L}$ at screening or at least 300 cells $/ \mu \mathrm{L}$ at some time during the previous year. Study-related blood eosinophil counts were carried out by a central laboratory. The original protocols were approved by local or study research ethics committees and conducted in accordance with good clinical practice guidelines and the Declaration of Helsinki.

\section{Treatment}

Patients in MENSA were randomly assigned to mepolizumab, administered as either a $75-\mathrm{mg}$ intravenous (IV) dose or a 100-mg subcutaneous (SC) dose, or matched placebo for 32 weeks [3]. Patients in MUSCA were randomly assigned to mepolizumab $100 \mathrm{mg}$ SC dose, or matched placebo for 24 weeks [4]. The current analysis was restricted to the 100-mg SC dose.

\section{Lung Function}

Peak flow was measured using an electronic peak flow meter ASMA-1 (Vitalograph Ltd., UK), which transmitted the peak flow value to the electronic diary (eDiary, PHT Corporation, Boston MA). The data was downloaded from the eDiary device to a centralized server at each visit.

In this post hoc analysis, daily data on AM PEF were summarized into weekly averages to assess a weekly change from baseline AM PEF analysis in the first 4 weeks of treatment and 4-weekly averages to assess a 4-weekly change from baseline in AM PEF analysis for the entire duration of the study. Analyses were performed overall and by stratifying patients into the following baseline blood eosinophil thresholds: $\geq 150$ cells $/ \mu \mathrm{L}, \geq 300$ cells $/ \mu \mathrm{L}$, and $\geq 500$ cells/ $\mu \mathrm{L}$. Baseline blood eosinophil ranges $(<150$ cells $/ \mu \mathrm{L}, 150$ cells $/ \mu \mathrm{L}$ to $<300$ cells $/ \mu \mathrm{L}$, and 300 cells $/ \mu \mathrm{L}$ to $<500$ cells $/ \mu \mathrm{L}$ ) were also assessed.

\section{Other Assessments}

Annualized rate of exacerbations, SGRQ score, ACQ-5 score, pre- and post-bronchodilator $\mathrm{FEV}_{1}$, and safety assessments including immunogenicity, adverse events, and serious adverse events were also evaluated. The results of these assessments have been reported elsewhere $[3,4]$.

\section{Statistical Analysis}

This post hoc analysis was based on the modified intent-to-treat (mITT) population for MENSA and MUSCA, including all randomized patients who received at least one dose of study medication.

Daily AM PEF data were summarized into weekly and four-weekly averages for each patient. Weekly AM PEF values for the first week of each study and four-weekly AM PEF values for the duration of each study were analyzed using a mixed model repeated measures model in each study separately. The model included covariates of treatment group, baseline AM PEF, region, age, sex, smoking history, atopy, baseline maintenance oral corticosteroid (OCS) use, exacerbations in the year prior to study start (categorized as 2, 3, $\geq 4$, included as an ordinal variable), visit, and interaction terms for visit by treatment and visit by baseline AM PEF. This 
analysis was carried out using absolute AM PEF values as well as log-transformed values to obtain absolute and relative change from baseline estimates, respectively. Adjusted means and treatment effect estimates were generated for each study visit separately and for all study visits combined by applying equal weighting for each visit. Difference from placebo estimates from individual studies were then combined using a fixed-effect meta-analysis using inversevariance weighting. A stratified analysis was performed to obtain estimates within subgroups. All analyses were performed using SAS version 9 (SAS Institute, Cary, NC).

\section{Compliance with Ethics Guidelines}

The studies were conducted in accordance with the ethical principles of the Declaration of Helsinki, International Council for Harmonisation Good Clinical Practice (GCP), and the applicable country-specific regulatory requirements.

\section{RESULTS}

The ITT population included 468 patients from both MENSA and MUSCA, i.e., a total of 936 patients. Demographic characteristics were relatively similar in both placebo and mepolizumab groups (Table 1).

\section{AM PEF Individual Studies}

\section{MENSA Study}

Baseline AM PEF was comparable between the mepolizumab and placebo group (295 and 269 L/min), respectively. Early and significant increases from baseline (weeks 1 to 4 ) were noted in mean (SE) AM PEF in the mepolizumab group, 15 (2.7) L/min compared to $-2(2.8) \mathrm{L} /$ min in the placebo group $(p<0.001)$ (Fig. 1a). Improvement in AM PEF continued during weeks 5 to 8 in the mepolizumab group, 23 (3.8) $\mathrm{L} / \mathrm{min}$ ) compared to 0 (3.9) $\mathrm{L} / \mathrm{min}$ in the placebo group $(p<0.001)$. At weeks 9 to 12 , the mepolizumab group achieved 29 (4.4) L/min increase compared to $-1(4.4) \mathrm{L} / \mathrm{min}$ in the placebo group $(p<0.001)$. Improvements were sustained during weeks 13-20; at weeks 21-24 the mepolizumab group showed 30 (4.3) L/min improvement compared to $4(4.4) \mathrm{L} / \mathrm{min}$ in the placebo group $(p<0.001)$. At the end of the study period (weeks 29-32) there was an improvement in the mepolizumab group of 29 (4.6) $\mathrm{L} / \mathrm{min}$ compared to 1 (4.7) $\mathrm{L} / \mathrm{min}$ in the placebo group, $p<0.001$, with a mean change difference from placebo of 28 (95\% CI, 15, 41) L/min (Fig. 1a).

\section{MUSCA Study}

Baseline AM PEF was comparable between the mepolizumab and placebo group (312 and $294 \mathrm{~L} / \mathrm{min}$ ), respectively. Also in the MUSCA study early and significant increases from baseline (weeks 1 to 4 ) were noted in mean (SE) AM PEF in the mepolizumab group, 17 (2.5) L/min compared to $2(2.5) \mathrm{L} / \mathrm{min}$ in the placebo group $(p<0.001)$ (Fig. 1b). Improvements in AM PEF continued during weeks $5-8$ in the mepolizumab group, $22(3.4) \mathrm{L} / \mathrm{min}$ compared to 3 (3.4) $\mathrm{L} / \mathrm{min}$ in the placebo group $(p<0.001)$. At weeks $9-12$, the mepolizumab group demonstrated $22(3.8) \mathrm{L} / \mathrm{min}$ increase compared to 4 (3.7) $\mathrm{L} / \mathrm{min}$ in the placebo group $(p<0.001)$. At weeks 13 to 16 , the mepolizumab group achieved a similar increase of 21 (4.0) L/min compared to $4(4.0) \mathrm{L} / \mathrm{min}$ in the placebo group $(p=0.003)$. Improvements were maintained during weeks 17-20, the mepolizumab group maintained a $22(4.1) \mathrm{L} / \mathrm{min}$ increase compared to $4(4.1) \mathrm{L} / \mathrm{min}$ in the placebo group $(p=0.002)$. At the end of the study period (weeks 21-24), the mepolizumab group showed $22(4.3) \mathrm{L} / \mathrm{min}$ improvement compared to 3 (4.3) $\mathrm{L} / \mathrm{min}$ in the placebo group $(p=0.002)$, with a mean change difference from placebo of 19 (95\% CI 7, 31) L/min (Fig. 1b).

\section{AM PEF Meta-Analysis}

In the meta-analysis of the MENSA and MUSCA studies baseline AM PEF in the mepolizumab and placebo group was 304 and $283 \mathrm{~L} / \mathrm{min}$, respectively. Early and significant increases in AM PEF from baseline (weeks 1-4) were noted in the mepolizumab group. A mean change 
Table 1 Patient demographics and baseline characteristics (combined MENSA and MUSCA studies, ITT population)

\begin{tabular}{|c|c|c|}
\hline & $\begin{array}{l}\text { Placebo } \\
N=468\end{array}$ & $\begin{array}{l}\text { Mepolizumab } \\
N=468\end{array}$ \\
\hline \multicolumn{3}{|l|}{ Gender, $n(\%)$} \\
\hline Female & $283(60)$ & $265(57)$ \\
\hline \multicolumn{3}{|l|}{ Age } \\
\hline Mean (SD) & $50.9(13.6)$ & $50.4(14.3)$ \\
\hline \multicolumn{3}{|l|}{ Race category, $n(\%)$} \\
\hline White & $407(87)$ & $404(86)$ \\
\hline Asian & $38(8)$ & $38(8)$ \\
\hline African-American/African heritage & $10(2)$ & $15(3)$ \\
\hline Other & $13(3)$ & $11(2)$ \\
\hline Body mass index $\left(\mathrm{kg} / \mathrm{m}^{2}\right)(\mathrm{SD})$ & $28(6.0)$ & $28.1(6.4)$ \\
\hline Asthma duration, years (SD) & $19.6(14.8)$ & $19.9(13.9)$ \\
\hline \multicolumn{3}{|l|}{ Baseline blood eosinophils } \\
\hline Geometric mean (SD log) & $335(0.92)$ & $296(1.08)$ \\
\hline$<150$ cells $/ \mu \mathrm{L}, n(\%)$ & $73(16)$ & $91(19)$ \\
\hline 150 to $<300$ cells $/ \mu \mathrm{L}, n(\%)$ & $121(26)$ & $119(25)$ \\
\hline 300 to $<500$ cells $/ \mu \mathrm{L}, n(\%)$ & $112(24)$ & $97(21)$ \\
\hline$\geq 500$ cells $/ \mu \mathrm{L}, n(\%)$ & $160(34)$ & $159(34)$ \\
\hline Missing, $n(\%)$ & $2(<1)$ & $2(<1)$ \\
\hline Asthma exacerbations in the previous year, mean (SD) & $3.1(2.2)$ & $3.3(2.4)$ \\
\hline Patients on maintenance OCS, $n(\%)$ & $111(24)$ & $116(25)$ \\
\hline Baseline pre-bronchodilator \% predicted $\mathrm{FEV}_{1}$, mean (SD) & $60(17)$ & $59(17)$ \\
\hline Baseline \% reversibility $\mathrm{FEV}_{1}$, mean (SD) & $23(21)$ & $25(22)$ \\
\hline Baseline SGRQ score, mean (SD) & $46.5(19.3)$ & $47.6(18.6)$ \\
\hline Baseline ACQ-5 score, mean (SD) & $2.2(1.2)$ & $2.2(1.2)$ \\
\hline
\end{tabular}

$A C Q$ asthma control questionnaire, $F E V_{1}$ forced expiratory volume in $1 \mathrm{~s}, I T T$ intent-to-treat, $O C S$ oral corticosteroid, $S D$ standard deviation, $S G R Q$ St. Georges Respiratory Questionnaire

difference from placebo of $8(95 \%$ CI 3,13$) \mathrm{L} /$ $\min (p<0.001)$ was seen during the first week (Fig. 2a) with a steady increase overtime. At the end of week 4, AM PEF mean (SD) increased in the mepolizumab group $18(2.4) \mathrm{L} / \mathrm{min}$ compared to $1(2.4) \mathrm{L} / \mathrm{min}$ in the placebo group $(p<0.001)$. Improvement in AM PEF continued during weeks 5 to 8 in the mepolizumab group,
22 (2.6) $\mathrm{L} / \mathrm{min}$ compared to 1 (2.6) $\mathrm{L} / \mathrm{min}$ in the placebo group $(p<0.001)$. Changes reached a plateau at weeks 9 to 12 , the mepolizumab group achieved $25(2.9) \mathrm{L} / \mathrm{min}$ increase compared to $2(2.9) \mathrm{L} / \mathrm{min}$ in the placebo group $(p<0.001)$. Improvements were sustained as observed in the individual studies during weeks 13 to 20 . At weeks 21 to 24 , the mepolizumab 

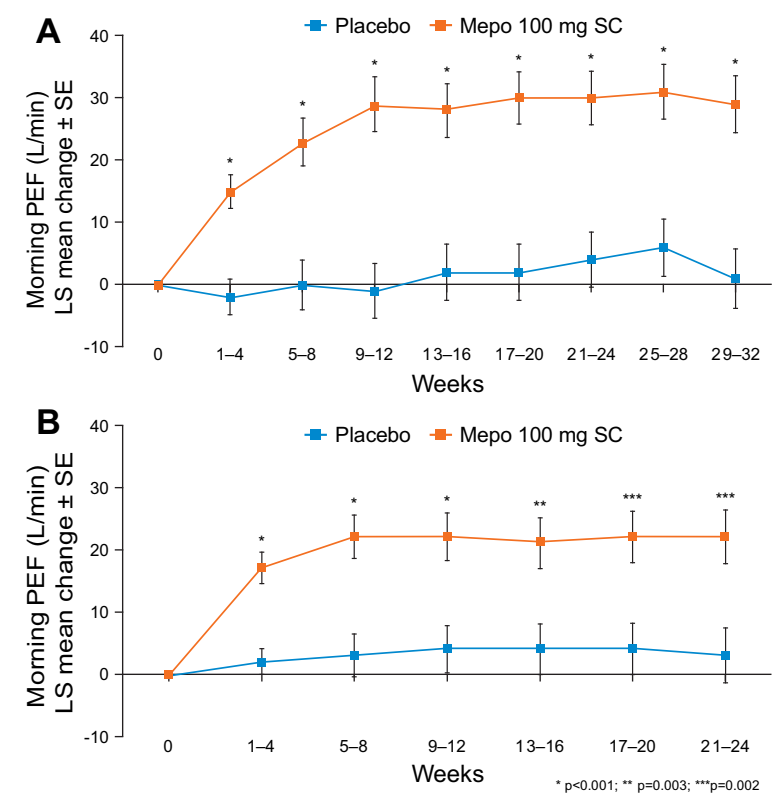

Fig. 1 Changes in AM PEF (L/min) in the a MENSA study and b MUSCA study
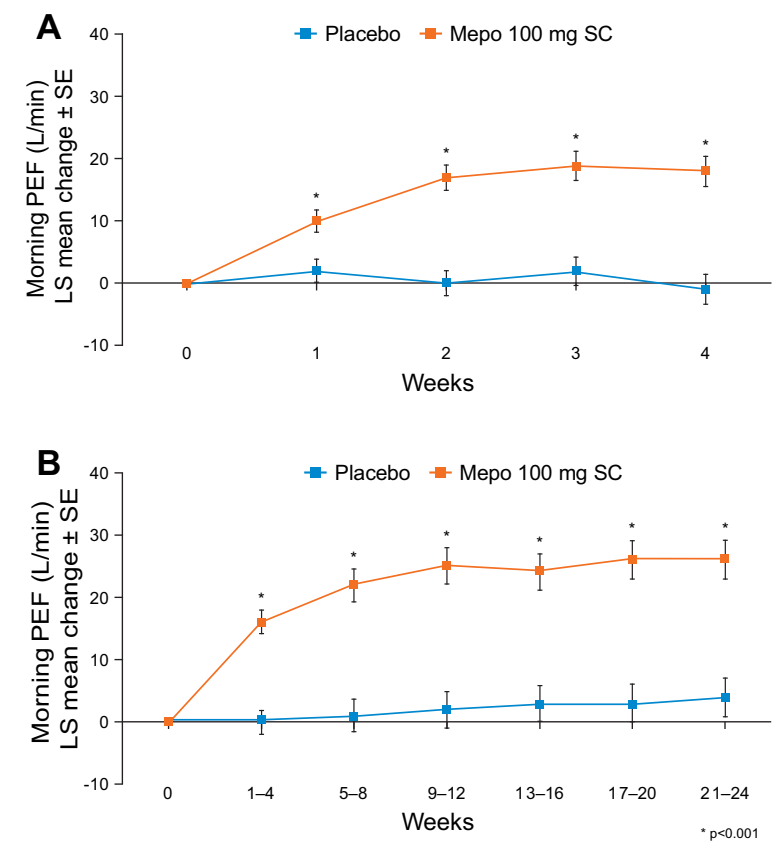

Fig. 2 Changes in AM PEF ( $\mathrm{L} / \mathrm{min})$ in the combined MENSA and MUSCA studies a during the first 4 weeks of treatment with mepolizumab and $\mathbf{b}$ up to week 24

group showed 26 (3.0) L/min improvement compared to $4(3.1) \mathrm{L} / \mathrm{min}$ in the placebo group $(p<0.001)$, with a mean change difference from placebo of 22 (95\% CI, 14, 31) L/min, $p<0.001$ (Fig. 2b). We also present the data as percentage change from baseline. Similarly, changes were seen early during the first 4 weeks following treatment with mepolizumab $(6 \%$ difference from placebo, $p<0.001)$ and continued by week 32 (12\% difference from placebo, $p<0.001$ ), the last 8 weeks correspond to MENSA alone (Fig. 1-S, supplemental material).

\section{Changes by Eosinophil Counts}

The population was analyzed using four primary thresholds: $<150$ cells $/ \mu \mathrm{L}, \geq 150$ cells $/ \mu \mathrm{L}$, $\geq 300$ cells $/ \mu \mathrm{L}$, and $\geq 500$ cells $/ \mu \mathrm{L}$. Significant increases from baseline at the end of the study period were noted in mean (SE) AM PEF in all the mepolizumab groups in the meta-analysis. The $<150$ cells $/ \mu \mathrm{L}$ group (represented also by patients enrolled on the basis of a historical $\geq 300$ cells $/ \mu \mathrm{L}$ ) treated with mepolizumab had an increase of $9(5.5) \mathrm{L} / \mathrm{min}$, compared to $-5(6.3) \mathrm{L} / \mathrm{min}$ in the placebo group, with a mean difference of $13 \mathrm{~L} / \mathrm{min}(95 \% \mathrm{CI}-4,30)$ $(p=0.126)$. The $\geq 150$ cells $/ \mu \mathrm{L}$ group treated with mepolizumab showed an increase of 27 (2.8) $\mathrm{L} / \mathrm{min}$ compared to $4(2.7) \mathrm{L} / \mathrm{min}$ in the placebo group $(p<0.001)$, with a mean difference from placebo of 24 (95\% CI 16, 32) L/min, $p<0.001$. The $\geq 300$ cells $/ \mu \mathrm{L}$ group showed an increase of $35(3.5) \mathrm{L} / \mathrm{min}$ compared to 8 (3.4) L/ min in the placebo group $(p<0.001)$, with a mean difference from placebo of 27 (95\% CI 17, 37) $p<0.001$. The threshold of $\geq 500$ cells $/ \mu \mathrm{L}$ increased $42(4.8) \mathrm{L} / \mathrm{min}$ compared to $8(4.8) \mathrm{L} /$ min in the placebo group $(p<0.001)$, with a mean difference from placebo of 34 (95\% CI 20, 47) L/min, $p<0.001$ (Fig. 3).

We also analyzed changes at the end of the observational period by blood eosinophil ranges: 150 to $<300$ cells $/ \mu \mathrm{L}$ and 300 to $<500$ cells/ $\mu \mathrm{L}$. This analysis was performed to better understand PEF changes over a range of peripheral eosinophil counts. The 150 to $<300$ cells/ $\mu \mathrm{L}$ group treated with mepolizumab improved $12(4.2) \mathrm{L} / \mathrm{min}$ compared to -8 (4.2) $\mathrm{L} / \mathrm{min}$ in the placebo group, with a mean difference of $19 \mathrm{~L} / \mathrm{min}(95 \% \mathrm{CI} 7,31), p=0.002$. The 300 to $<500$ cells $/ \mu \mathrm{L}$ mepolizumab group 


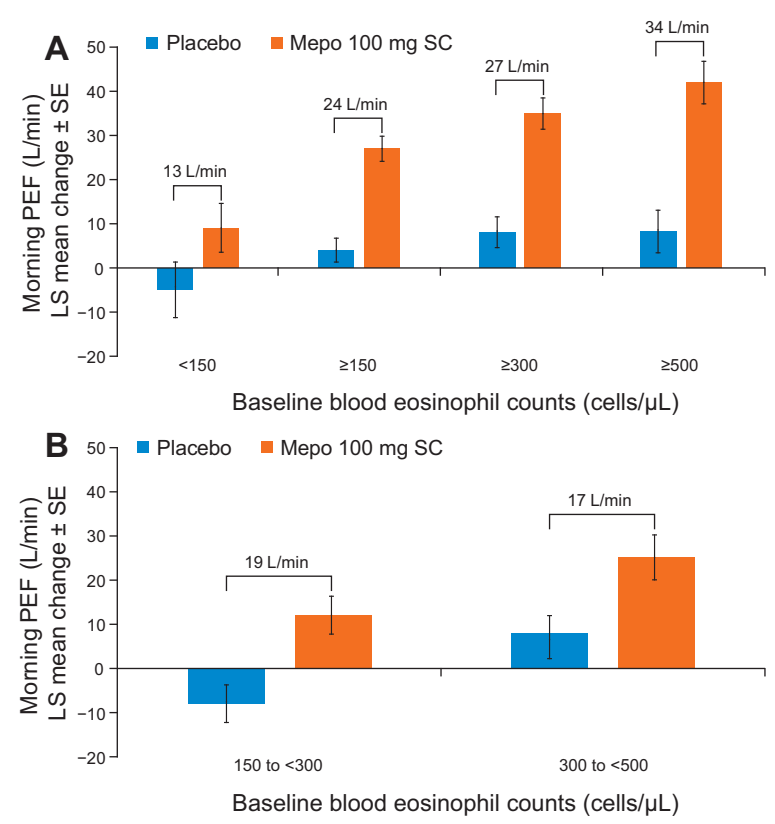

Fig. 3 Changes in AM PEF (L/min) in the combined MENSA and MUSCA studies by a blood eosinophil thresholds and $\mathbf{b}$ across all blood eosinophil ranges

showed an increase of 25 (5.1) L/min, compared to $7(4.8) \mathrm{L} / \mathrm{min}$ in the placebo group, with a mean difference of $17 \mathrm{~L} / \mathrm{min}(95 \%$ CI 3, 31) $p=0.017$ (Fig. 3b).

\section{DISCUSSION}

In this analysis mepolizumab demonstrated early and meaningful improvement in lung function as measured by daily AM PEF in patients with severe eosinophilic asthma. The data was consistent across the individual studies, MENSA and MUSCA [3, 4]. Results from this analysis in patients with a baseline blood eosinophil count of at least 150 cells $/ \mu \mathrm{L}$ or at least 300 cells $/ \mu \mathrm{L}$ in the previous year treated with mepolizumab $100 \mathrm{mg}$ SC had a mean AM PEF difference from placebo of $22 \mathrm{~L} / \mathrm{min}$. There was a positive association between the improvement in lung function and increasing baseline blood eosinophil count. This association is consistent with a recent meta-analysis in patients with severe eosinophilic asthma evaluating a range of eosinophil thresholds demonstrating greater improvement in exacerbation reduction for mepolizumab with increasing baseline blood eosinophil counts [13].

These findings warrant further discussion. Early studies with mepolizumab were inconsistent in terms of changes in lung function $[1,2]$, while these studies demonstrated clear benefit in exacerbation reduction. This enabled a better understanding of the relationship between eosinophilic inflammation and asthma pathobiology. The mepolizumab target population was refined during the mepolizumab development program with the incorporation of key markers to predict response including blood eosinophil count of at least 150 cells $/ \mu \mathrm{L}$ at screening or 300 cells/ $\mu \mathrm{L}$ in the past 12 months, at least two exacerbations in the past 12 months, and high dose ICS plus another controller $[3,4]$. On the basis of this profile, patients in MENSA and MUSCA who received mepolizumab $100 \mathrm{mg}$ SC had a 98-mL and 120 -mL improvement in $\mathrm{FEV}_{1}$, respectively. While there is limited published PEF data available with biologics, other anti-IL-5 biologics have shown improvements in lung function measured by changes in $\mathrm{FEV}_{1}$ [14-16].

Recently, Chupp and colleagues reported a post hoc analysis from the SIROCCO and CALIMA studies of benralizumab on changes in AM PEF [17]. The data were derived from patients with a baseline blood eosinophil count of $\geq 300$ cells $/ \mu \mathrm{L}$. In SIROCCO, changes over the first week in AM PEF from baseline with benralizumab (Q8W) were $14.05 \mathrm{~L} / \mathrm{min}$ vs. $7.16 \mathrm{~L} / \mathrm{min}$ in placebo (estimated difference $6.89 \mathrm{~L} / \mathrm{min}$ ) and in CALIMA were 14.58 vs. $8.75 \mathrm{~L} / \mathrm{min}$, in placebo (estimated difference $5.83 \mathrm{~L} / \mathrm{min}$ ). At the end of the treatment period, in SIROCCO benralizumab (Q8W) changes were 46.09 vs. $23.33 \mathrm{~L} / \mathrm{min}$, in placebo (estimated difference $22.76 \mathrm{~L} / \mathrm{min}$ ) and in CALIMA were 47.63 vs. $23.97 \mathrm{~L} / \mathrm{min}$, in placebo (estimated difference $23.66 \mathrm{~L} / \mathrm{min}$ ). By comparison, when we analyzed pooled data from the MENSA and MUSCA studies in patients with a blood eosinophil count of $\geq 300$ cells $/ \mu \mathrm{L}$, at the end of the treatment period mepolizumab improved AM PEF by 35 vs. $8 \mathrm{~L} / \mathrm{min}$ in placebo, with a mean difference from placebo of $27 \mathrm{~L} / \mathrm{min}$. While the improvements with mepolizumab were larger 
than that seen with benralizumab, it is important to recognize that these are indirect comparisons and therefore cannot directly inform on comparative effectiveness.

The relationship between inflammation and physiological changes is complex. Mepolizumab alters the growth, proliferation, and migration of eosinophils by blocking IL-5 [18]. Eosinophilia in lung tissue is driven by IL- 5 and by the recruitment of eosinophils to the lung via the production of chemokines [18, 19]. In patients with severe asthma, several molecular mechanisms have been identified that might account for reduced steroid responsiveness [20]. We hypothesize that some of these altered molecular mechanisms in patients with severe asthma are circumvented by targeted therapies such as mepolizumab, allowing additional clinical benefits on top of ICS therapy, such as those shown in this report.

Peak flow measurements are important for monitoring asthma. However, most of the current studies in severe asthma evaluating lung function focus on $\mathrm{FEV}_{1}$ measured by standard spirometry [21]. There are several practical advantages in using PEF $[22,23]$. Since the PEF is reached very early in a forced expiratory maneuver, the forced expiratory maneuver can be of brief duration and is therefore relatively easy to perform. PEF can be measured with either a mechanical or an electronic peak flow meter. The use of an electronic peak flow meter offers the capability to store multiple readings over time for future download and review with the date and time stamped [19]. Adherence is likely to be better with self-recording electronic meters than with manual flow meters that require data to be recorded in a daily diary. Accordingly, PEF is suitable for individual testing at home during clinical trials [2-4, 6], in the workplace to study occupation-related exposures [24], and in the outpatient healthcare setting [25]. Overall, the collection of daily PEF offers the ability to capture fluctuations in lung function, including periods during and after an exacerbation. In contrast, $\mathrm{FEV}_{1}$ measured at the clinic (e.g., every 4 weeks in clinical trials) provides only a cross-sectional view of the patient's status at the time of the visit, which could be influenced by an ongoing exacerbation or its related treatment, particularly in the more severe patients. Long-term PEF monitoring is recommended by treatment guidelines for patients with severe asthma, or those with impaired perception of airflow limitation [26]. A minimal clinically important difference (MCID) in PEF has not been fully established, but in asthma clinical trials a change in AM PEF between 19 and $25 \mathrm{~L} / \mathrm{min}$ from baseline is considered clinically significant $[27,28]$.

\section{CONCLUSION}

Asthma treatment guidelines [26] highlight the need to achieve asthma control, maintain normal activity levels and lung function, as well as minimizing the risk of exacerbations with few side effects. These results support improvements in lung function across defined eosinophil thresholds and augment the benefits in other markers of asthma control seen with mepolizumab. A limitation of this post hoc analysis is the retrospective nature of the methodology. In conclusion, these findings highlight the utility of PEF in clinical trials and the fact that eosinophil counts are associated with rapid, consistent, and clinically meaningful changes in lung physiology following treatment with mepolizumab when assessed in concert with disease severity, treatment intensity, and exacerbation history.

\section{ACKNOWLEDGEMENTS}

Funding. The study, the article processing charges, and the Open Access fee were funded by GlaxoSmithKline (study ID 208091).

Editorial Assistance. Editorial support (in the form of formatting and grammatical editing) was provided by Susan Parker, PhD, of Fishawack Indicia Ltd, Oxford, UK funded by GSK.

Authorship. All named authors meet the International Committee of Medical Journal Editors (ICMJE) criteria for authorship for this 
article, take responsibility for the integrity of the work as a whole, and have given their approval for this version to be published.

Authorship Contributions. Conception and design: HO, AM-G, J-PL, MF, FA, NG, EB, SY, and $\mathrm{MK}$; Acquisition of data: $\mathrm{HO}, \mathrm{FA}, \mathrm{NG}, \mathrm{EB}$, SY; Data analysis and interpretation: $\mathrm{HO}, \mathrm{AM}-\mathrm{G}$, J-PL, MF, FA, NG, EB, SY, and MK. The first draft was written by the lead author, HO. All authors were involved in development of all stages of the manuscript, revising it critically for important intellectual content. All authors provided final approval of the version submitted for publication. All authors are accountable for the accuracy and integrity of the work.

Disclosures. Hector Ortega is an employee of GSK and owns stock/stock options in GSK. Jean-Pierre Llanos is an employee of GSK and owns stock/stock options in GSK. Mark Forshag is an employee of GSK and owns stock/stock options in GSK. Frank Albers is an employee of GSK and owns stock/stock options in GSK. Necdet Gunsoy is an employee of GSK and owns stock/stock options in GSK. Eric $S$ Bradford is an employee of GSK and owns stock/stock options in GSK. Steven W Yancey is an employee of GSK and owns stock/stock options in GSK. Andrew Menzies-Gow has attended advisory boards with GSK, AstraZeneca, Novartis, Hoffman La Roche, Boehringer Ingelheim, and Teva. He has received lecture fees from Novartis, Vectura, Napp, AstraZeneca, Boehringer Ingelheim, and Teva. He has attended international conferences with AstraZeneca, Napp, and Boehringer Ingelheim. He has participated in clinical trials with GSK, AstraZeneca, Boehringer Ingelheim, and Hoffman La Roche and has consultancy agreements with AstraZeneca and Vectura. Monica Kraft has received research funding (paid to University of Arizona) from Chiesi, Sanofi, and Genentech/Roche. She has attended advisory boards with AstraZeneca, Teva, and Regeneron.

Compliance with Ethics Guidelines. The studies were conducted in accordance with the ethical principles of the Declaration of Helsinki, International Council for Harmonisation Good
Clinical Practice (GCP), and the applicable country-specific regulatory requirements.

Open Access. This article is distributed under the terms of the Creative Commons Attribution-NonCommercial 4.0 International License (http://creativecommons.org/licenses/ by-nc/4.0/), which permits any noncommercial use, distribution, and reproduction in any medium, provided you give appropriate credit to the original author(s) and the source, provide a link to the Creative Commons license, and indicate if changes were made.

\section{REFERENCES}

1. Haldar P, Brightling CE, Hargadon B, et al. Mepolizumab and exacerbations of refractory eosinophilic asthma. N Engl J Med. 2009;360:973-84.

2. Pavord ID, Korn S, Howarth P, et al. Mepolizumab for severe eosinophilic asthma (DREAM): a multicentre, double-blind, placebo-controlled trial. Lancet. 2012;380:651-9.

3. Ortega HG, Liu MC, Pavord ID, et al. Mepolizumab treatment in patients with severe eosinophilic asthma. N Engl J Med. 2014;371:1198-207.

4. Chupp G, Bradford SE, Albers CF, et al. The efficacy of mepolizumab add-on therapy on health-related quality of life and markers of asthma control in patients with severe eosinophilic asthma: a randomised controlled trial. Lancet Respir Med. 2017;5:390-400.

5. Nair P, Pizzichini MM, Kjarsgaard M, et al. Mepolizumab for prednisone-dependent asthma with sputum eosinophilia. $\mathrm{N}$ Engl J Med. 2009;360:985-93.

6. Bel EH, Wenzel SE, Thompson PJ, et al. Oral glucocorticoid-sparing effect of mepolizumab in eosinophilic asthma. N Engl J Med. 2014;371:1189-97.

7. Flood-Page P, Swenson C, Faiferman I, et al. A study to evaluate safety and efficacy of mepolizumab in patients with moderate persistent asthma. Am J Respir Crit Care Med. 2007;176:1062-71.

8. GlaxoSmithKline. Mepolizumab $\left(\mathrm{NUCALA}^{\circledR}\right)$ US prescribing information, 2015. https://www. gsksource.com/pharma/content/dam/GlaxoSmith Kline/US/en/Prescribing_Information/Nucala/pdf/ NUCALA-PI-PIL.PDF. Accessed March 15, 2017. 
9. GlaxoSmithKline. Mepolizumab (NUCALA $\left.{ }^{\circledR}\right)$ EU summary of product characteristics, 2017. http:// www.ema.europa.eu/docs/en_GB/document_library/ EPAR_-_Product_Information/human/003860/WC50 0198037.pdf. Accessed March 15, 2017.

10. GlaxoSmithKline. Meta-analysis of studies MEA115588 and 200862 of mepolizumab (SB240563) to evaluate changes in AM PEF in severe eosinophilic asthma (eTrack Study Identifier 208091). http://www.gsk-clinicalstudyregister.com/ study/208091?study_ids208091)\#ps. Accessed August 18, 2017.

11. American Thoracic Society. Proceedings of the ATS workshop on refractory asthma: current understanding, recommendations, and unanswered questions. Am J Resp Crit Med Med 2000;162:2341-51.

12. Chung KF, Wenzel SE, Brozek JL, et al. International ERS/ATS guidelines on definition, evaluation and treatment of severe asthma. Eur Respir J. 2014;43:343-73.

13. Ortega HG, Yancey SW, Mayer B, et al. Severe eosinophilic asthma treated with mepolizumab stratified by baseline eosinophil thresholds: a secondary analysis of the DREAM and MENSA studies. Lancet Respir Med. 2016;4:549-56.

14. Castro M, Zangrilli J, Wechsler ME, et al. Reslizumab for inadequately controlled asthma with elevated blood eosinophil counts: results from two multicentre, parallel, double-blind, randomised, placebo-controlled, phase 3 trials. Lancet Respir Med. 2015;3:355-66.

15. FitzGerald JM, Bleecker RE, Nair P, et al. Benralizumab, an anti-interleukin-5 receptor $\alpha$ monoclonal antibody, as add-on treatment for patients with severe, uncontrolled, eosinophilic asthma (CALIMA): a randomised, double-blind, placebocontrolled phase 3 trial. Lancet. 2016;388:2128-41.

16. Bleecker RE, FitzGerald JM, Chanez P, et al. Efficacy and safety of benralizumab for patients with severe asthma uncontrolled with high-dosage inhaled corticosteroids and long-acting $\beta 2$-agonists (SIROCCO): a randomised, multicentre, placebo-controlled phase 3 trial. Lancet. 2016;388:2115-27.

17. Chupp G, Ferguson TG, Hirsh I, Goldman M, Zangrilli GJ, Trudo F. Benralizumab treatment produces rapid changes in morning peak expiratory flow in patients with severe, uncontrolled eosinophilic asthma. J Allergy Clin Immunol. 2018;141:AB15.

18. Fulkerson PC, Rothenberg ME. Targeting eosinophils in allergy, inflammation and beyond. Nat Rev Drug Discov. 2013;12:117-29.

19. Foster SP, Mould WA, Yang M, et al. Elemental signals regulating eosinophil lung accumulation. Immunol Rev. 2001;179:173-81.

20. Barnes PJ. Corticosteroid resistance in patients with asthma and chronic obstructive pulmonary disease. J Allergy Clin Immunol. 2013;131:636-45.

21. Wand FP, Wang F-P, Liu T, et al. Efficacy and safety of anti-interleukin-5 therapy in patients with asthma: a systematic review and meta-analysis. PLoS One. 2016;11(11):e0166833. https://doi.org/ 10.1371/journal.pone.0166833.

22. Reddel HK, Salome CM, Peat JK, Woolcock AJ. Which index of peak expiratory flow is most useful in the management of stable asthma? Am J Respir Crit Care Med. 1995;151(5):1320-5.

23. Tepper SR, Wise SR, Covar R, et al. Asthma Outcomes: pulmonary physiology. J Allergy Clin Immunol. 2012;129:S65-87.

24. Chiry S, Cartier A, Malo J-L, et al. Comparison of peak expiratory flow variability between workers with work-exacerbated asthma and occupational asthma. Chest. 2007;132:483-8.

25. Beasley R, Cushley M, Holgate TS. A self-management plan in the treatment of adult asthma. Thorax. 1989;44:200-4.

26. Global Initiative for Asthma (GINA). Global strategy for asthma management and prevention. 2016. http://ginasthma.org/2016-gina-report-globalstrategy-for-asthma-management-andprevention/. Accessed March 15, 2017.

27. Santanello NC, Zhang J, Seidenberg B, et al. What are minimal important changes for asthma measures in a clinical trial? Eur Respir J. 1999;14:23-7.

28. Boushey HA, Sorkness CA, King TS, et al. Daily versus as-needed corticosteroids for mild persistent asthma. N Engl J Med. 2005;352:1519-28. 